\title{
Erratum: Do, D.-T., et al. Hybrid Satellite-Terrestrial Relay Network: Proposed Model and Application of Power Splitting Multiple Access. Sensors 2020, 20, 4296
}

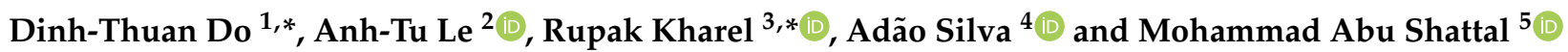 \\ 1 Department of Computer Science and Information Engineering, College of Information and \\ Electrical Engineering, Asia University, Taichung City 41354, Taiwan \\ 2 Faculty of Electronics Technology, Industrial University of Ho Chi Minh City (IUH), \\ Ho Chi Minh City 700000, Vietnam; leanhtu@iuh.edu.vn \\ 3 Department of Computing and Mathematics, Manchester Metropolitan University, Manchester M15 6BH, UK \\ 4 Instituto de Telecomunicações (IT) and Departamento de Eletrónica, Telecomunicações e Informática (DETI), \\ University of Aveiro, 3810-193 Aveiro, Portugal; asilva@av.it.pt \\ 5 Department of Computer Science and Engineering, The Ohio State University, 2015 Neil Avenue, \\ Columbus, OH 43212, USA; abushattal@ieee.org \\ * Correspondence: dodinhthuan@asia.edu.tw (D.-T.D.); r.kharel@mmu.ac.uk (R.K.)
}

Citation: Do, D.-T.; Le, A.-T.; Kharel, R.; Silva, A.; Shattal, M.A. Erratum: Do, D.-T., et al. Hybrid Satellite-Terrestrial Relay Network: Proposed Model and Application of Power Splitting Multiple Access. Sensors 2020, 20, 4296. Sensors 2021, 21, 186. https://doi.org/10.3390/ s21010186

Received: 13 October 2020 Accepted: 17 December 2020 Published: 29 December 2020

Publisher's Note: MDPI stays neutral with regard to jurisdictional claims in published maps and institutional affiliations.

Copyright: (c) 2020 by the authors. Licensee MDPI, Basel, Switzerland. This article is an open access article distributed under the terms and conditions of the Creative Commons Attribution (CC BY) license (https: / / creativecommons.org/ licenses/by/4.0/).
The authors wish to make the following erratum to this paper [1].

Funding is incorrect and must be replaced by the following Funding:

Funding: This work is funded by FCT/MCTES through national funds and, when applicable, cofunded by EU funds under the project UIDB/50008/2020-UIDP/50008/2020.

The authors would like to apologize for any inconvenience caused to the readers by these changes.

\section{Reference}

1. Do, D.-T.; Le, A.-T.; Kharel, R.; Silva, A.; Shattal, M.A. Hybrid Satellite-Terrestrial Relay Network: Proposed Model and Application of Power Splitting Multiple Access. Sensors 2020, 20, 4296. [CrossRef] [PubMed] 